Please send trade news information and illustrations to Terry Mordecai at the BDJ, 64 Wimpole Street, London W1G 8YS. Trade news is supplied as a service to the reader and does not imply endorsement by the BDJ. Normal and prudent research should be exercised before purchase or use of any product mentioned.

\section{Prestige Dental}

The Aero Etcher Intra Oral Blaster from Prestige Dental is an an intra-oral airblaster that Prestige Dental claims improves adhesion and contains unique features not found in other air-blasters.

Some of the features include: a trigger activation for left or right handed users, a quick connect/ disconnect for easy transport, and autoclavable head to eliminate cross-infection. The removable head swivels $360^{\circ}$ for universal access and operates at a low 40psi air pressure. It has two abrasive flow settings, and a replaceable tungsten tip that resists wear.

For more information on this and other Prestige products phone $01274-721567$ or emailinfo@prestige-dental.co.uk.

Reader response number 52

\section{Dr Denti's new range}

Grafton International have launched a brand new range of Dr Denti products. These over-the-counter retail products have been developed specifically to help your patients once they have left the surgery.

Refit is one choice for those patients who may have gone on holiday with only a temporary crown in place, or for those who may be concerned that a crown may fall out when they are unable to visit the surgery quickly.

Clove-Gel herbal tincture is a natural preparation of clove oil and peppermint oil, both of which are well known for their sedative and healing properties. Grafton claims Clove-Gel is the right tincture for patients to use if they are suffering from toothache. For more information phone on $0800581303 . \quad$ Reader response number 53

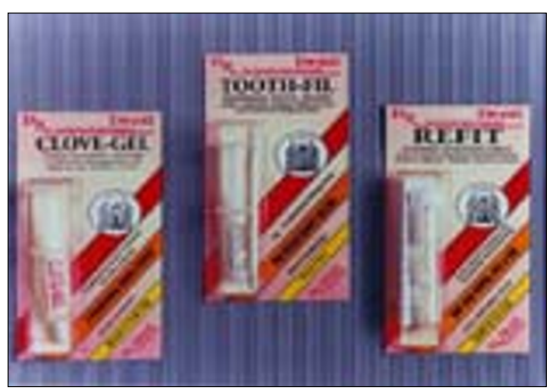

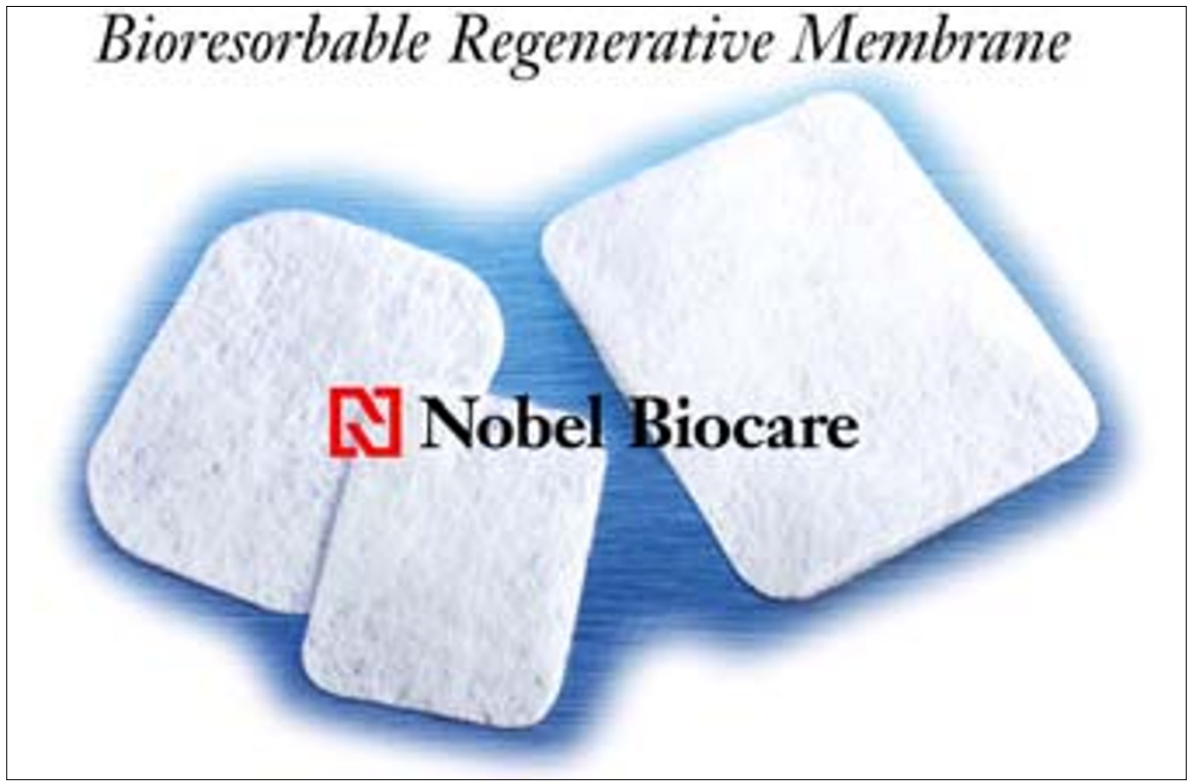

\section{A membrane material from Nobel Biocare}

A new bioresorbable regenerative membrane that works in conjunction with bone substitutes is now available from Nobel Biocare. The "gore resolut adapt Regenerative Membrane" is a soft, supple, drapeable and easy-to-handle material that is intended to aid in the healing of periodontal and bone defects. Noble Biocare also claims that It adapts readily to defective margins, holds bone-graft particles in place, and retards epithelial migration into the defect.

Noble Biocare also claims the new membranes provide barrier function for eight to ten weeks. They are fabricated from a fibre web composed of bioresorbable copolymers glycolide (PGA) and trimethylene carbonate (TMC). Long used in bioabsorbable sutures, surgical meshes, and implantable devices, Noble Biocare claims the material has a wellknown history of safety and does not carry the risk of animal-source contamination. For more information phone 01895430650.

Reader response number 51

\section{The Endo-Core system from Metalor}

To help dentists with endo treatment, Metalor have launched the Endo-Core System which they claim is a highly versatile system, suited for a number of endodontic applications.

Metalor claims the cylindro-conical design conforms closely to the anatomical root shape of the tooth while the upper cylindrical portion of the post provides improved retention and avoids unnecessary enlargement of the root canal opening.

The Endo-Core system consists of a) StylePost, composed of biocompatible fibreglass embedded in a resin matrix, b) MP-Posts, adhesive and retentive, are available in a range of biocompatible materials, c)Endo-Snap Press Fastening Posts, Titanium posts specifically designed for the fastening of removable partial dentures and overdentures. For more information call 01923891900. Reader response number 54

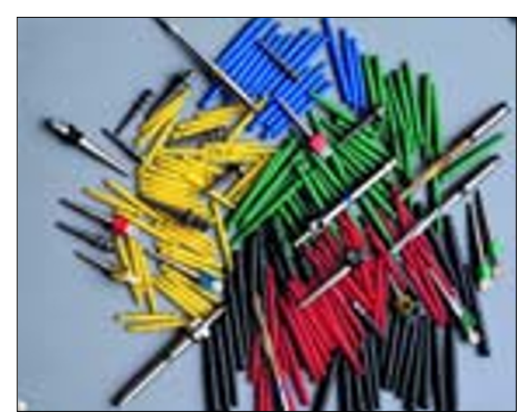




\section{Get a Winnie the Pooh mug from Oral-B}

Oral B is set to introduce a novel promotion, which they claim is sure to be popular with all practice members. During November and December orders of four-dozen children's toothbrushes will be despatched with a free Winnie-the-Pooh porcelain mug.

The mugs are part of a collection; there are four in total, each one representing a season of the year. Place an order for twelve dozen children's toothbrushes and you'll receive the complete set.

Oral-B launched Stages, a range of children's toothbrushes earlier in the year. Stages recognises that children's oral care needs evolve as they grow. Differences occur in the development of teeth and gums as, in motor skills and co-ordination, and in levels of motivation.

For more information contact your local representative.

Reader response number 59

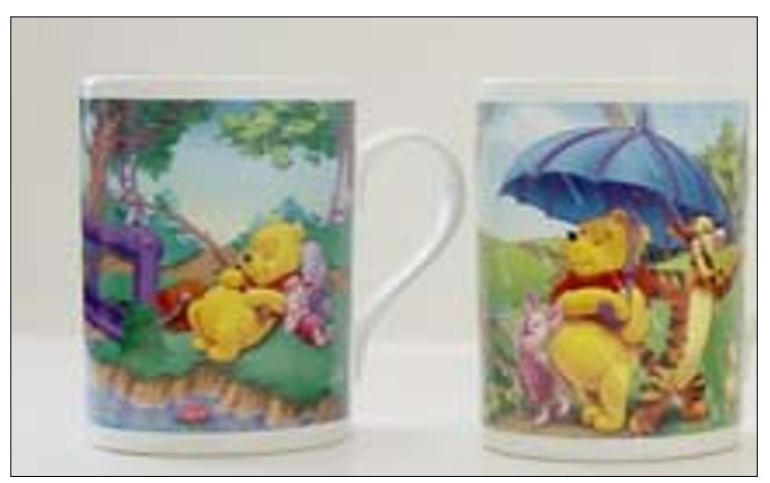

\section{Petros and Erisma aim to imrove you business}

Dental Business Solutions, advisers to dentists and dental teams, have recently launched Petros and Erisma services. Brochures are now available that explain the practical help and guidance on offer to the profession.

Dental Business Solutions claims that the service has been developed to meet the fundamental compliance requirements of all dentists. It includes accounts preparation for principals, associates and other members of the dental team, ensuring they comply with statutory requirements, tax returns and payroll (an increasingly complex and difficult area).

Erisma offers dentists a wide range of specialist skills that provide support, guidance and direction as their practices grow. It covers practice management and marketing, benchmarking, consultancy and business planning, human resources, patient perception measurement and analysis and specialist tax advice.

For more information phone 01844 260111 or email info@dbs.org.uk. Reader response number 60

\section{The CIC v8 Explorer from MEDiVison}

MEDiVison is pleased to launch the upgraded version of CIC v8 Explorer. The upgrade includes a complete revamp of the patient leaflet module, with new illustrated leaflets, leaflet previews and a new area for the practices' own documents. Screens can now be personalised with logos, and headings and animation text can now be modified.

MEDiVision announced its new upgrade CIC V8 Explorer, which includes 20 new 3D sequences and a completely new 'explorer' interface, just prior to the London Showcase and have already been inundated with upgrade requests.

The upgrade which costs £99 + vat, and covers all existing practice licences. The upgrade is supported by many of the leading names in the industry. For more information phone 01908 265565.

Reader response number 61

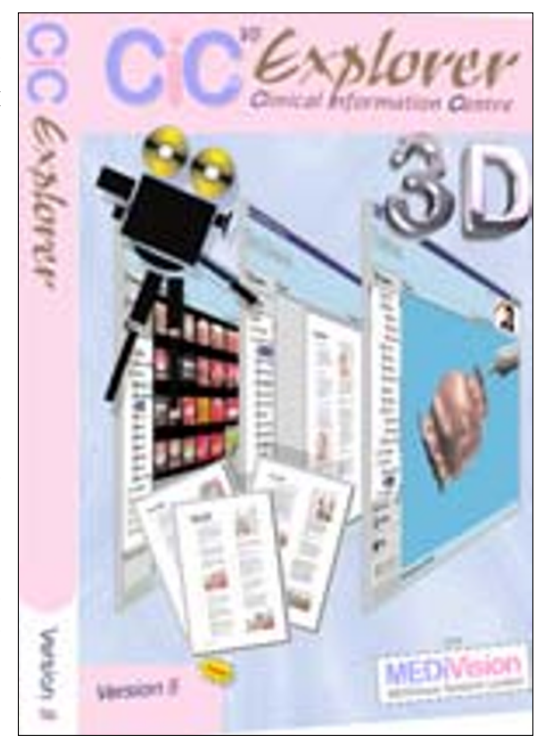

